\title{
Growth of High-Quality Multicrystalline Silicon Ingot through the Cristobalite Seeded Method
}

\author{
Yunyang $\mathrm{Yu}^{1}$, Junjing Ding ${ }^{1}$, Wenliang $\mathrm{Chen}^{1}$, Zhaoyu Zhang ${ }^{2}$, Xucheng Zhou ${ }^{2}$, Genxiang Zhong ${ }^{3}$ and Xinming \\ Huang ${ }^{1,3}$ \\ 1. School of Materials Science and Engineering, Nanjing Tech University, Nanjing, Jiangsu 210009, China \\ 2. Donghai JA Solar Technology Co., Ltd., Lianyungang, Jiangsu 222300, China \\ 3. JA Solar Holdings Co., Ltd., Feng Tai District, Beijing 100160, China
}

\begin{abstract}
In this paper, an effective method for grain quality control in directional solidification (DS) by using cristobalite particles as seeds is proposed. The cristobalite seeds paved on the bottom of the crucible significantly enhanced the crystal quality of the multicrystalline silicon ingot in comparison with fused quartz seeds. The distribution of initial grain sizes at the ingot bottom was small and uniform. Crystals with lower dislocation density showed a higher and more uniform minority carrier lifetime compared to that produced by the fused quartz seeded growth method used in industry. A higher average solar cell conversion efficiency of about $0.09 \%$ in absolute value was obtained using the cristobalite seeded ingot (18.31\%) in comparison with that using a fused quartz seeded ingot (18.22\%) under the same cell production process.
\end{abstract}

Key words: Directional solidification, seed crystal, nucleation, dislocation, solar cell.

\section{Introduction}

Multicrystalline silicon (mc-Si) grown by directional solidification method has become the main solar cell material because of its low production cost and high throughput. However, the energy conversion efficiency of solar cells based on mc-Si is still 1.5\% lower than that of single-crystal silicon cells because of numerous defects in the crystal, such as grain boundaries, dislocation clusters and impurities. Thus, improving the mc-Si quality by reducing the density of defects is especially important for the photovoltaic industry. In recent years, seed-assisted casting method has been widely used to grow the high-quality $\mathrm{mc}-\mathrm{Si}$ ingots, since it is useful in controlling the dislocation density and improving the cell performance [1-4]. Zhu et al. [2] used mc-Si particles as external seeds for nucleation and grain growth control, and crystals with high minority carrier lifetime and much low

Corresponding author: Xinming Huang, Ph.D., professor of photovoltaic materials, research fields: silicon crystal growth and solar cell. dislocation density were obtained. However, a longer low minority carrier lifetime area usually called the red zone appeared at the ingot bottom because of the existence of unmelted seeds [5, 6], which greatly lowered the yield and increased the cost of casting compared to the conventional ingot grown without seeds.

In order to solve this problem, granular fused quartz is used as heterogeneous seeds instead of mc-Si to manipulate nucleation in industry and many studies because of its a lot of advantages, such as high purity, high melting point, good wettability and much low cost [7-9]. Nevertheless, owing to heterogeneous nucleation, the crystal quality is generally not as good as that grown with mc-Si seeds, although the ingot yield increased. Recently, Zhang et al. [3] reported a novel method for grain control by quartz coating with an ingenious geometry structure that provided numerous heterogeneous nucleation points, and they obtained an ingot with uniform grain size distribution and low dislocation density close to that of mc-Si 
seed-assisted ingot. However, it is difficult to apply to mass production because of the complicated operation for seed coating preparation.

In this study, we investigated a convenient approach for controlling grain growth by using crystalline cristobalite. Appropriate size of cristobalite particles was sprayed on the bottom of the crucible to promote nucleation and assist the growth of columnar grains. Moreover, another $\mathrm{Si}$ ingot using ordinary fused quartz particles as seeds was grown for comparison, and the difference in the initial grain size, minority carrier lifetime, dislocation clusters density and solar cell efficiency between the two ingots was investigated.

\section{Experimental}

\subsection{Seed and Coating Preparation}

The crucibles with inner dimensions of $890 \mathrm{~mm} \times$ $890 \mathrm{~mm} \times 480 \mathrm{~mm}$ were used in this experiment. Firstly, seed particles of 40-50 mesh size were evenly sprinkled on the crucible bottom, and a slurry made from high-purity suspended silica powder was used to strengthen. Secondly, two layers of silicon nitride coating were added for the ease of mold release. The first layer approximately $200 \mu \mathrm{m}$ thick was brushed on the top of the seeds at room temperature. After drying, the crucible was transferred to a rotator and the temperature was gradually increased to $55{ }^{\circ} \mathrm{C}$. The second silicon nitride layer with a thickness of $70 \mu \mathrm{m}$ was then uniformly sprayed on the first silicon nitride coating. It should be noted that the second coating layer was not as dense as the first one, which is to

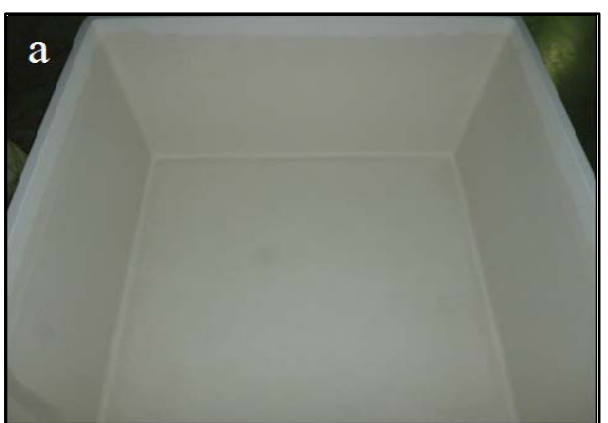

Fig. 1 (a) Picture of the crucible after spraying, (b) enlarged morphology of the silicon nitride coated seeds on the bottom of the crucible. facilitate the silicon melt through the upper coating and contact with the surface of the seeds. Fig. 1 shows the picture of the crucible after spraying (Fig. 1a) and the enlarged morphology of the silicon nitride coated seeds on the bottom of the crucible (Fig. 1b), respectively.

\subsection{Crystal Growth and Analysis}

An industrial furnace of Jinggong JJL500 directional solidification system was used for ingot cast in this experiment. The $\mathrm{Si}$ feedstock charge amount was about $520 \mathrm{Kg}$. In the DS system, a thermal gradient of about $10 \mathrm{~K} / \mathrm{cm}$ was set for the crystal growth, and the average growth rate was controlled at about $1.2 \mathrm{~cm} / \mathrm{h}$. Furthermore, a silicon ingot grown with fused quartz seeds was cast under the same growth recipes. When the casting process was finished, both ingots with heights of about 300 mm were obtained.

The grain morphology of the ingot bricks was analyzed by infrared imaging (Semilab, IRB-50), and the minority carrier lifetime of the silicon bricks was measured using microwave photoconductance decay (Semilab, WT-2000). Silicon wafers with a thickness of $180 \mu \mathrm{m}$ were cut from the bricks by a standard wire saw for further measurements. Laboratory offline PL instrument (BT imaging, LIS-R1) and industrial online PL instrument (Hennecke, HE-WI-04) were used to observe the dislocation distribution in the silicon wafers. Fabrication and performance testing of the solar cells were performed by Yangzhou JA Solar Technology Co., Ltd.

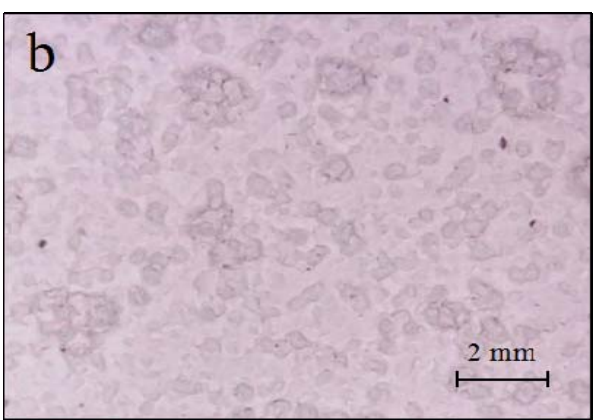




\section{Results and Discussion}

\subsection{Initial Grain Size Distribution}

After squaring, each ingot was cut into 25 bricks, as shown in Fig. 2a. The infrared images for the longitudinal cross sections of bricks B11 to B15 from ingots grown with fused quartz seeds and cristobalite seeds are shown in Figs. $2 b$ and $2 c$, respectively. For both two ingots, thin and vertical columnar grains are observed at the brick bottom, and the grain size increases with the growth height.

To further investigate the grain size, silicon wafers were cut $2 \mathrm{~mm}$ away from the ingot bottom of brick $\mathrm{C} 13$ of both ingots, and the initial grain morphology images are shown in Figs. $3 a$ and $3 b$, respectively. From Fig. 3, it is easy to found that the ingot grown with cristobalite seeds (Fig. 3b) has a smaller and more uniform initial grain size than the ingot grown with fused quartz seeds (Fig. 3a). Fig. 4 shows the distribution statistics of the initial grain size for two cut wafers. The grain size distribution of cristobalite seeded ingot is apparently more concentrated, and the average diameter for the fused quartz seeded and cristobalite seeded ingots are 3.57 and $3.01 \mathrm{~mm}$, respectively. This means the initial grain size of cristobalite seeded ingot is $20 \%$ smaller than that of fused quartz seeded ingot. In general, small and uniform grain size distribution is really beneficial to inhibit the multiplication of dislocations because of the blocking effect of grain boundaries on dislocation slipping. The smaller grain size contains more grain boundaries, which makes it easier to terminate dislocations in these regions [10].

In addition, a number of dendritic grains were found in the silicon wafers from both ingots, as shown in the red circles in Fig. 3, which result from undercooling at the initial growth stage [11, 12]. However, the cristobalite seeded ingot (Fig. 3b) had the a

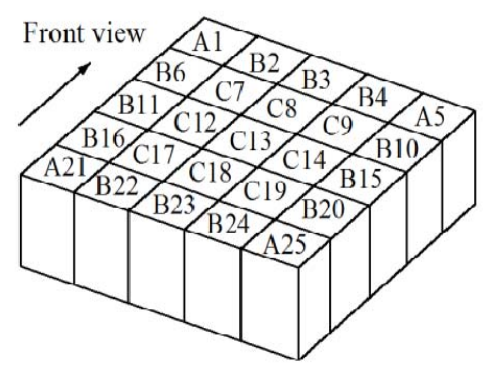

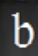

C

Fig. 2 (a) Brick number of an ingot after squaring, (b) \& (c) infrared scan of longitudinal grain distribution of bricks B11-B15 from the ingots grown with fused quartz seeds (b) and grown with cristobalite seeds (c).
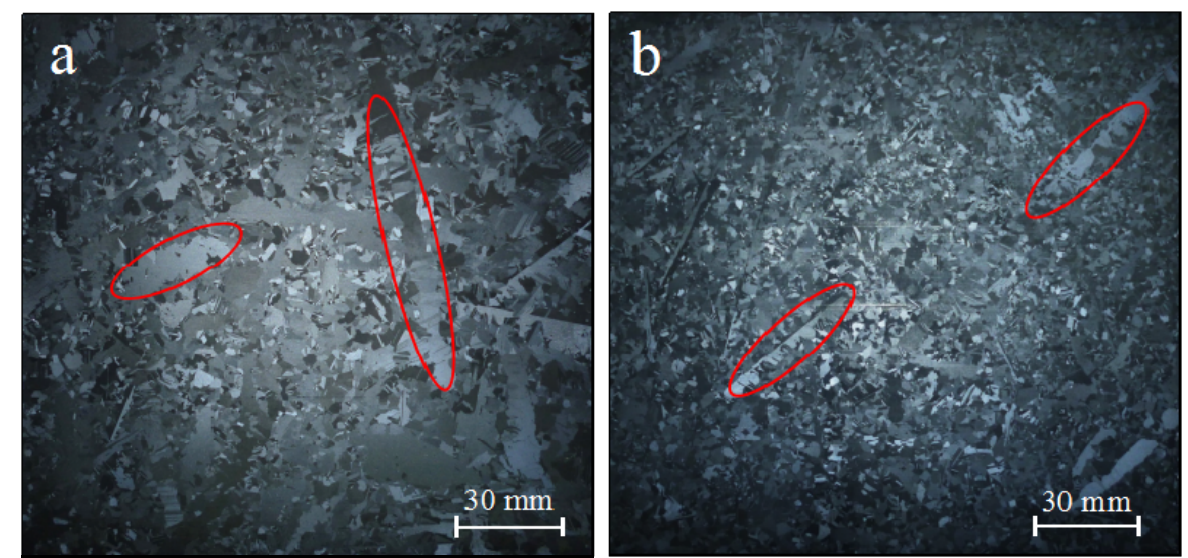

Fig. 3 Morphology of the grains in the silicon wafers from brick C13 at a growth height of $2 \mathrm{~mm}$ : (a) grown with fused quartz seeds and (b) grown with cristobalite seeds. 


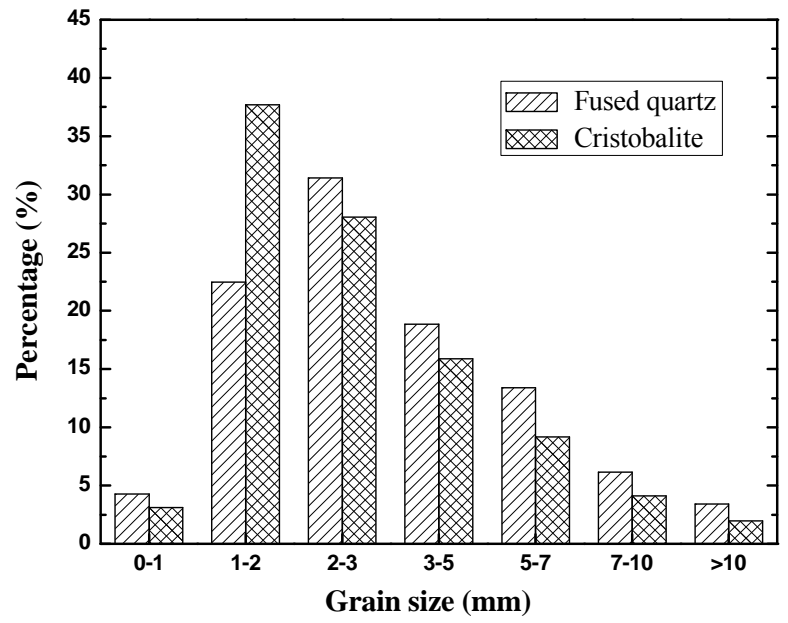

Fig. 4 Distribution of initial grain size for two ingots grown with different seeds.

smaller and less dendrites than the ingot grown with fused quartz seeds (Fig. 3a). The difference in the initial grain sizes at the brick bottom for the two ingots can be explained as follows. Because the cristobalite crystal exists in the form of $\alpha$ phase at high temperature, it has a cubic structure similar to that of silicon. Thus, there is a lower interfacial energy between the cristobalite seed and silicon crystal than the fused quartz seed, which can effectively reduce the heterogeneous nucleation energy barrier and accelerate the growth of nuclei. As a result, a high density of nuclei was formed and restricted the horizontal growth of dendrites, and then small and uniform initial grains were obtained.

\subsection{Minority Carrier Lifetime Distribution}

The minority carrier lifetime is one of the key factors that affect the performance of solar cells. Fig. 5 shows the longitudinal minority carrier lifetime distribution of the ingot grown (Fig. 5a) with fused quartz seeds and (Fig. 5b) with cristobalite seeds, respectively. From the figure, it can be found that both ingots have a total red area height of about $50 \mathrm{~mm}$, including the bottom and top, which means a similar ingot yield for the two types of seeds under the same charge. However, the minority carrier lifetime of the cristobalite seeded ingot showed a higher and more
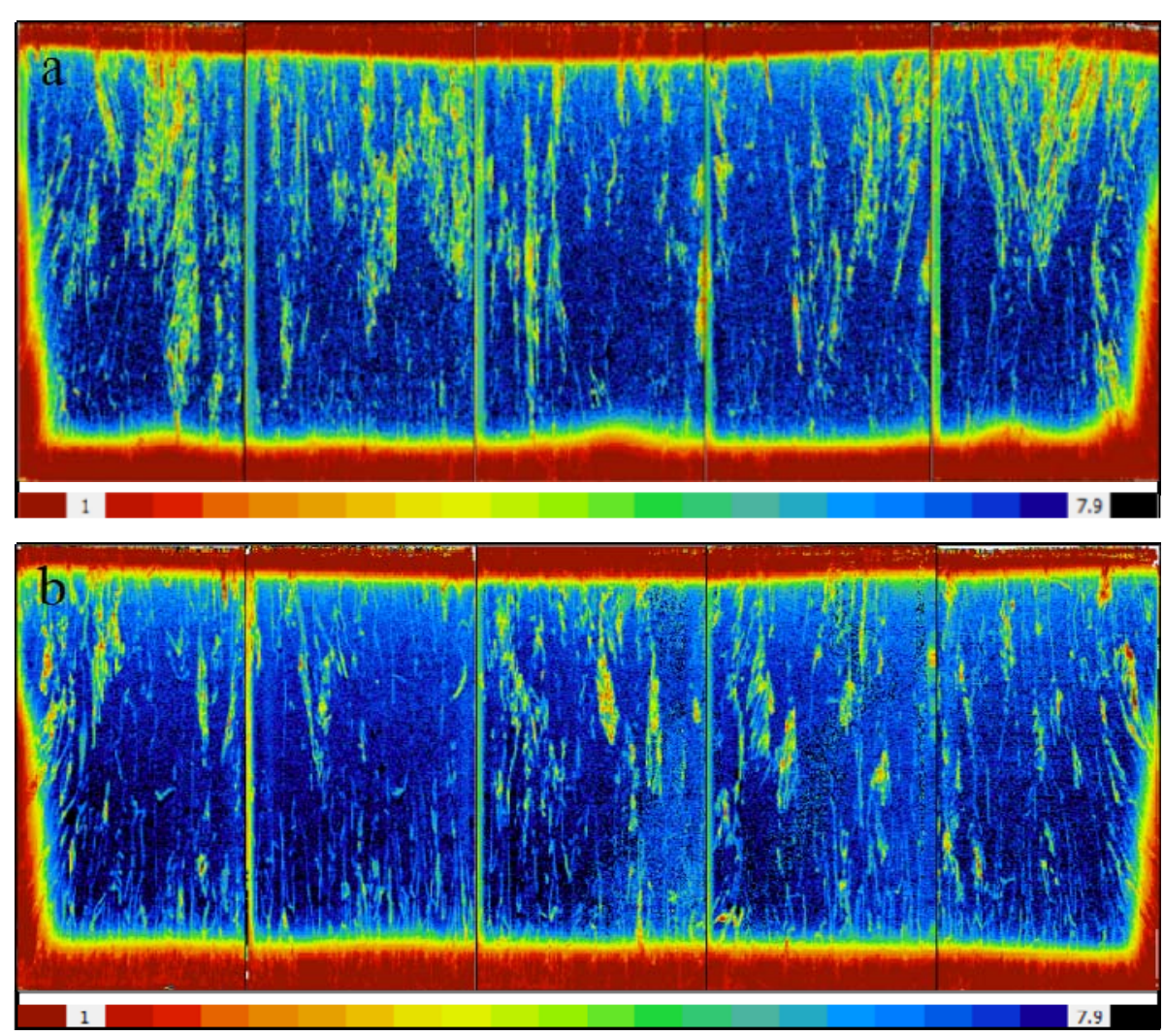

Fig. 5 Longitudinal minority carrier lifetime mapping of bricks B11-B15 from the ingot grown with (a) fused quartz seeds and (b) cristobalite seeds. 
uniform distribution than the fused quartz seeded ingot. Numerous large waterfall-like regions with low lifetime value were observed in the top part of the ingot grown with fused quartz seeds. It is supposed that rapid multiplication of dislocations occurred in the later period of crystal growth, resulting in the generation of massive minority carrier recombination centers, and eventually reduced the value of the minority carrier lifetime.

\subsection{Density of Dislocation Clusters}

To investigate the distribution of dislocations, wafers cut from the positions of bottom, middle and top parts of the two ingots were analyzed by offline PL detecting system (BT imaging, LIS-R1) and the PL images are shown in Fig. 6. The dark areas represent a high density of dislocation clusters while the other bright areas represent a low density of dislocation clusters. Meanwhile, the ratio of dark area to the total wafer area calculated by online PL-Algo software (Hennecke, HE-WI-04) is used to determine the dislocation clusters density level, and the dislocation clusters ratio data of the wafers from the bottom to the top of bricks $\mathrm{C} 13$ from each ingot is shown in Fig. 7.

From Figs. 6 and 7, it is easy to find that the dislocation density increases with the growth height in both ingots, and the cristobalite seeded ingot has a lower density of dislocation clusters than the fused quartz seeded ingot, except at the bottom of the ingot. A little higher dislocation density was observed in the bottom wafer from the cristobalite seeded ingot. This phenomenon may be related to the nucleation mechanism. As the $\alpha$-cristobalite seed has a different lattice constant from the silicon crystal, nuclei grown along the lattice of cristobalite crystals may bring about distortion and result in the formation of misfit dislocations. However, the dislocation clusters density of the cristobalite seeded ingot was found decreased subsequently, which may benefit from the small and uniform initial grain size distribution. A large amount of random grain boundaries blocked the dislocation propagation and released thermal stress, which led to a
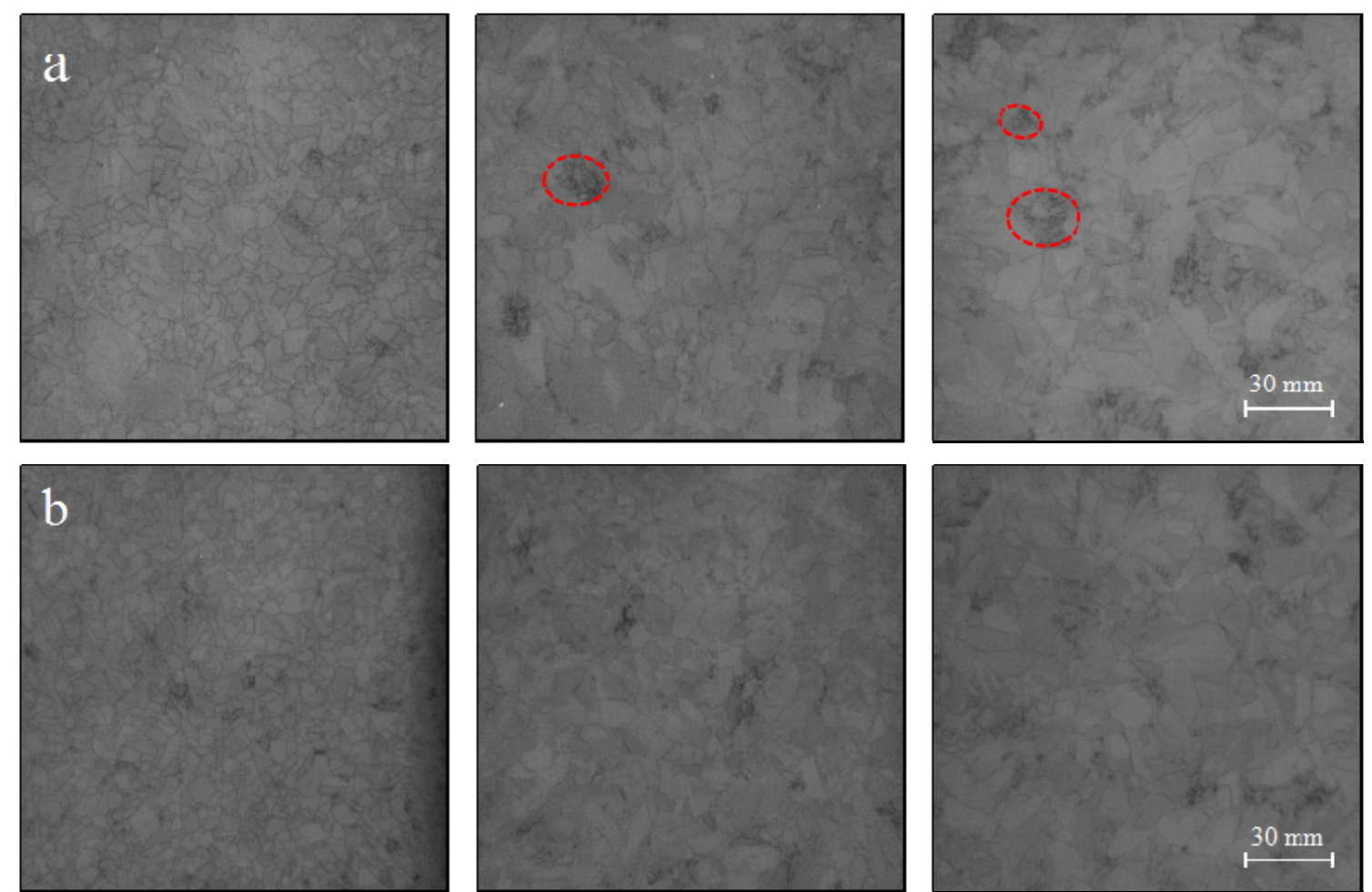

Fig. 6 PL images of the wafers from bottom, middle and top parts of brick C13 from the ingot grown with (a) fused quartz seeds and (b) cristobalite seeds. 


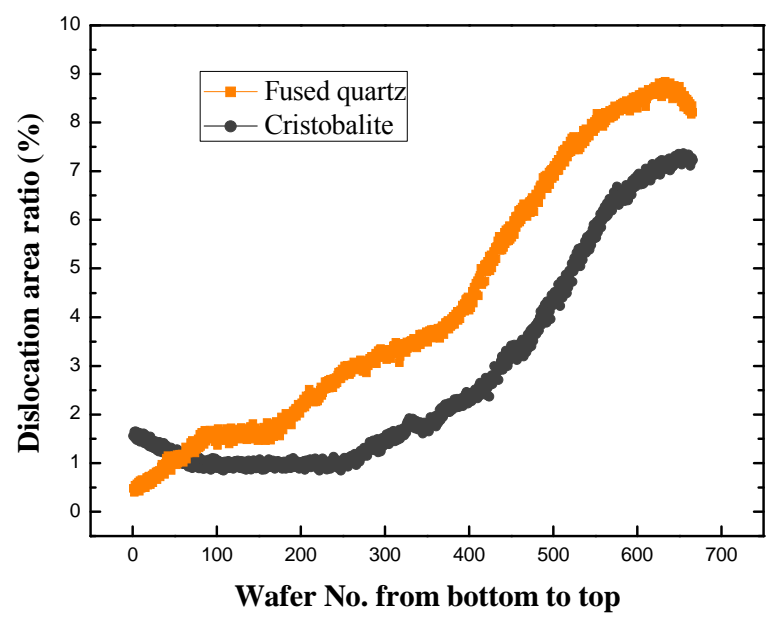

Fig. 7 Ratio of dislocation area to the total area for the wafers along growth direction corresponding to different ingots.

lower density of dislocation clusters [13, 14].

When the crystal grew to the medium height, the density of dislocation clusters in the cristobalite seeded ingot increased, but the grain sizes were still uniform (Fig. 6b). While the dislocation clusters density of the fused quartz seeded ingot was obviously higher, and the most dislocations were concentrated in the regions of relatively small grains (Fig. 6a). This is mainly because grains with different sizes have different growth rates, and the large grains driven by surface energy began to squeeze and annex the small grains nearby, which resulted in more stress [2]. When crystals grew to the later stage, the growth competition became more intense because of the expansion of the size gap between grains, and the more extrusion stress contributed to the faster multiplication of dislocation clusters. Ultimately, a significantly higher dislocation clusters density was observed in the top wafer from the ingot grown with fused quartz seeds. Furthermore, the dislocation clusters ratio data for the whole wafers was collected, as shown in Table 1, and the statistical results showed that the mean dislocation clusters area ratio for the fused quartz seeded ingot and cristobalite seeded ingot was $4.05 \%$ and $3.32 \%$, respectively. This means that the dislocation clusters density of the cristobalite seeded ingot is $18.02 \%$ lower than that grown with ordinary fused quartz, and the cristobalite seeds have a clear advantage in the aspect of dislocation control.

\subsection{Cell Performance}

Fig. 8 shows the solar cell efficiency distribution for the two types of ingot. A total of 7,200 silicon wafers chosen from regions $\mathrm{A}, \mathrm{B}$ and $\mathrm{C}$ at a ratio of 4:12:9 from each ingot were fabricated into cells using the same standard cell production process, which can represent the quality of the wafers for the whole ingot. The results were shown that the average solar cell conversion efficiency for the fused quartz seeded ingot and cristobalite seeded ingot were $18.22 \%$ and $18.31 \%$, respectively. In other words, the solar cell efficiency of the cristobalite seeded ingot was enhanced by $0.09 \%$ due to the improvement of crystal quality in comparison with that of fused quartz seeded ingot, and corresponding to an average output power of solar cells increased from 4.42 to $4.46 \mathrm{~W}$. Moreover, the cells based on cristobalite seeded wafers also had a narrower efficiency distribution, which was beneficial to increase the proportion of high performance solar cells.

Table 1 Dislocation clusters area ratio for the wafers from different regions of two ingots.

\begin{tabular}{lllll}
\hline $\begin{array}{l}\text { Seeds } \\
\text { regions }\end{array}$ & $\mathrm{A}$ & $\mathrm{B}$ & $\mathrm{C}$ & $\begin{array}{l}\text { Average } \\
\text { value }\end{array}$ \\
\hline Fused quartz & 4.46 & 4.01 & 3.67 & 4.05 \\
Cristobalite & 3.98 & 3.15 & 2.82 & 3.32 \\
\hline
\end{tabular}

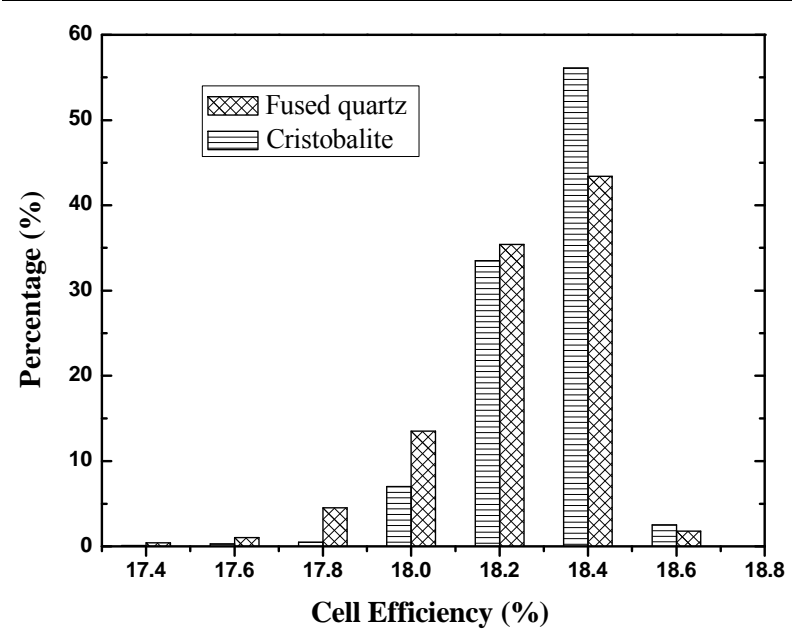

Fig. 8 Efficiency distribution of the solar cells for two ingots. 


\section{Conclusions}

The cristobalite seeded growth of high-quality mc-Si ingot for the grain size control and dislocation suppression has been investigated. A silicon ingot with small and uniform initial grain size distribution was obtained using the cristobalite seeds. The minority carrier lifetime was higher and more uniform than that of the fused quartz seeded ingot because of the lower dislocation clusters density. Moreover, the average conversion efficiency of solar cells fabricated with the cristobalite seeded ingot was about $0.09 \%$ higher than that of solar cells fabricated with the fused quartz seeded ingot under the same cell production process. This shows that the quality of mc-Si ingot produced by the cristobalite seeded growth method can be effectively improved, which is advantageous to increase the cost performance in mass production.

\section{Acknowledgments}

This work was partly supported by the Program for Changjiang Scholars and Innovative Research Team in University (PCSIRT) [Grant number IRT1146]; a project funded by the Priority Academic Program Development of Jiangsu Higher Education Institutions (PAPD); a project funded by the Natural Science Foundation of Jiangsu Higher Education Institutions [Grant number 13KJB430016]; and a project funded by the Natural Science Foundation of the Jiangsu Province [Grant number BK20141460].

\section{References}

[1] Lan, C. W., Yu, W. H., Yang, Y. M., Chou, H. S., Chen, Y. L., and Hsu, C. L. et al. 2014. "Crystalline Silicon Ingot and Silicon Wafer Therefrom." ROC Patent TWI452185B, filed 2011, and issued 2014.

[2] Zhu, D. D., Ming, L., Huang, M. L., Zhang, Z. Y., and Huang, X. M. 2014. "Seed-Assisted Growth of High-Quality Multi-Crystalline Silicon in Directional Solidification.” Journal of Crystal Growth 386 (January): 52-6.

[3] Zhang, H. L., You, D., Huang, C. L., Wu, Y. H., Xu, Y., and $\mathrm{Wu}$, P. 2016. "Growth of Multicrystalline Silicon Ingot with Both Enhanced Quality and Yield through Quartz Seeded Method.” Journal of Crystal Growth 435
(February): 91-7.

[4] Ding, J. J., Yu, Y. Y., Chen, W. L., Zhou, X. C., Wu, Z. Y., and Zhong, G. X. et al. 2016. "Effect of the Fused Quartz Particle Density on Nucleation and Grain Control of High-Performance Multicrystalline Silicon Ingots." Journal of Crystal Growth 454 (November): 186-91.

[5] Zhong, G. X., Yu, Q. H., Huang, X. M., and Liu, L. J. 2014. "Influencing Factors on the Formation of the Low Minority Carrier Lifetime Zone at the Bottom of Seed-Assisted Cast Ingots." Journal of Crystal Growth 402 (September): 65-70.

[6] Gao, B., Nakano, S., and Kakimoto, K. 2012. "Influence of Back-Diffusion of Iron Impurity on Lifetime Distribution near the Seed-Crystal Interface in Seed Cast-Grown Monocrystalline Silicon by Numerical Modeling." Journal of Crystal Growth 12 (December): 522-5.

[7] Brynjulfsen, I., and Arnberg, I. 2011. "Nucleation of Silicon on $\mathrm{Si}_{3} \mathrm{~N}_{4}$ Coated $\mathrm{SiO}_{2}$." Journal of Crystal Growth 331 (January): 64-7.

[8] Wong, Y. T., Hsieh, C. T., Lan, A., Hsu, C., and Lan, C. W. 2014. "The Effect of Silica Nucleation Layers on Grain Control of Multi-crystalline Silicon in Directional Solidification.” Journal of Crystal Growth 404 (October): 59-64.

[9] Yuan, Z., Huang, W. L. and Mukai, K. 2004. "Wettability and Reactivity of Molten Silicon with Various Substrates.” Applied Physics A 78 (March): 617-22.

[10] Ryningen, B., Stokkan, G., Kivambe, M., Ervik, T., and Lohne, O. 2011. "Growth of Dislocation Clusters During Directional Solidification of Multicrystalline Silicon Ingots." Acta Materialia 59 (December): 7703-10.

[11] Fujiwara, K., Pan, W. G., Usami, N., Sawada, K., Tokairin, M., and Nose, Y. et al. 2006. "Growth of Structure-Controlled Polycrystalline Silicon Ingots for Solar Cells by Casting." Acta Materialia 54 (July): 3191-7.

[12] Nakajima, K., Kutsukake, K., Fujiwara, K., Morishita, K., and Ono, S. 2011. "Arrangement of Dendrite Crystals Grown along the Bottom of $\mathrm{Si}$ Ingots Using the Dendritic Casting Method by Controlling Thermal Conductivity under Crucibles." Journal of Crystal Growth 319 (March): 13-8.

[13] Hsieh, C. C., Wu, Y. C., Lan, A., Hsu, H. P., Hsu, C., and Lan, C. W. 2015. "Comparison of Defect Formations in Solar Silicon Growth from Small Random and Large Oriented Seeds." Journal of Crystal Growth 419 (June): 1-6.

[14] Stokkan, G., Hu, Y., Mjøs, Ø., and Juel, M. 2014. "Study of Evolution of Dislocation Clusters in High Performance Multicrystalline Silicon." Solar Energy Materials and Solar Cells 130 (November): 679-85. 